Paino, J., Perera, S., Alashwal, A. and Rodrigo, M.N.N., 2019. Impact of fly-ash on carbon emissions in different concrete grades. In: Sandanayake, Y.G., Gunatilake, S. and Waidyasekara, A. (eds). Proceedings of the $8^{\text {th }}$ World Construction Symposium, Colombo, Sri Lanka, 8-10 November 2019, pp. 368-377. DOI: doi.org/10.31705/WCS.2019.37. Available at: https://2019.ciobwcs.com/papers

\title{
IMPACT OF FLY-ASH ON CARBON EMISSIONS IN DIFFERENT CONCRETE GRADES
}

\author{
Jacob Paino $^{1}$, Srinath Perera ${ }^{2}$, Ali Alashwal ${ }^{3}$ and M.N.N. Rodrigo ${ }^{4}$
}

\begin{abstract}
Concrete is one of the most used construction materials; however, it contributes to about 7\% of all carbon emissions. Various supplementary cementitious materials such as flyash have been considered to enhance concrete performance. There is a limitation of studies that address the influence of fly-ash on carbon reduction in different grades of concrete. Hence, the aim of this study is to analyse the impacts of fly-ash in concrete on carbon emissions in construction projects. A comparison between carbon emissions of portland cement concrete projects and fly-ash concrete projects was conducted using data collected from 20 construction projects in New South Wales, Australia. The results showed that higher the grade of concrete used, higher the carbon dioxide emissions, due to the increase of portland cement needed to achieve the higher grades of concrete. Introducing fly-ash to the concrete mix showed a significant reduction in carbon emissions. However, from the financial perspective, it was found that the rate per cubic metre of fly-ash concrete is $2.1 \%$ more expensive than standard concrete mixes. Therefore, the idea of adopting fly-ash into the concrete mix may not deliver cost savings as expected. Overall, this study provided clear insight into the effects of concrete usage on the environment and ways to reduce carbon emission.
\end{abstract}

Keywords: Building Construction; Carbon Emissions; Concrete; Fly-Ash.

\section{INTRODUCTION}

The use of concrete on large-scale construction projects has become a critical environmental issue with concrete being one of the main building materials used in structural and non-structural elements of construction projects. Portland cement is being used within the concrete as the main hydraulic binder providing concrete its strength and structural properties (Mehta, 2002). The production of Portland cement is a high contributor of the Carbon Dioxide $\left(\mathrm{CO}_{2}\right)$ emissions released to the atmosphere. The rapid expansion of the construction work in Sydney was regarded as a contributor to $\mathrm{CO}_{2}$ emissions in the past (Worrell et al., 2001). Currently, the many ongoing construction

\footnotetext{
${ }^{1}$ School of Computing, Engineering and Mathematics, Western Sydney University, Australia, 18407307@student.westernsydney.edu.au

${ }^{2}$ School of Computing, Engineering and Mathematics, Western Sydney University, Australia, Srinath.Perera@westernsydney.edu.au

${ }^{3}$ School of Computing, Engineering and Mathematics, Western Sydney University, Australia, A.Al-Ashwal@westernsydney.edu.au

${ }^{4}$ School of Computing, Engineering and Mathematics, Western Sydney University, Australia, n.rodrigo@westernsydney.edu.au
} 
projects in Western Sydney and in New South Wales are expected to have a similar impact.

Industrial waste products are not disposed as landfill and many materials can be developed into Supplementary Cementitious Materials (SCMs). Due to the massive usage of coal in power plants, there is a substantial amount of fly-ash being generated. The disposal or storing of fly-ash is very expensive, resulting in the need to find another usage for it (Siddique, 2011). Thus, fly-ash has been commonly added to the concrete mix. SCMs are recognised for the obvious benefits gained with regard to carbon emissions reduction because of the low amount of the calcium oxide in most SCMs. Some fly-ashes have a higher calcium oxide content, which could be used to replace limestone in clinker resulting in a $15 \%$ decrease in carbon emissions (Joseph and Tretsiakova-McNally, 2010). There is a limited number of studies that investigates how the addition of fly-ash contributes to reduce $\mathrm{CO}_{2}$ emissions in different concrete grades. Hence, this study attempts to highlight the effect of fly-ash on carbon emissions while considering the amount of cost incurred. The objectives of this study are to review the use of fly-ash in concrete compared to other SCMs, evaluate the environmental effect of supplementing fly-ash into the concrete production process, and analyse the financial effect of supplementing fly-ash into the concrete production process in construction projects.

\section{LITERATURE REVIEW}

\subsection{CONSTRUCTION CONCRETE}

Concrete is formed by mixing a chemically inert aggregate, a binder, chemical additives and water. It is the most commonly used structural material in the construction industry and is proven to be used more than any other man-made material in the world (Sentowski, 2009). It is a versatile material that allows the usage of different aggregates and cementitious materials, which ultimately changes many of the properties allowing concrete to be used for multiple purposes on a wide range of projects (Juenger and Siddique, 2015). Carbon emissions from cement production on this scale is what contributes to most of the $\mathrm{CO}_{2}$ released into the atmosphere (Aprianti, 2017).

According to Shi et al. (2008), there is roughly 10 billion tons of concrete produced each year in the modern construction industry. Aprianti (2017) and International Energy Agency (2019) has shown that cement production in concrete construction generates approximately $7 \%$ of all $\mathrm{CO}_{2}$ released into the atmosphere around the world. When all aspects of concrete construction are considered like energy usage and demolition waste, it shows that concrete is not an ideal construction material in regard to sustainable development, which is what large construction companies are beginning to acknowledge (Aprianti, 2017). In Australia, cement production accounts for around $1.3 \%$ of greenhouse gas emissions that are released, which is still the biggest contributor in the construction industry but significantly lower compared to the rest of the world (McLellan et al., 2011). Therefore, the need of introducing sustainable methods to reduce these carbon emissions has aroused (Rodrigo et al., 2019). The most common form of sustainable methods being tested in current concrete construction is the introduction of SCMs, which could be one of the means to achieve a significant $\mathrm{CO}_{2}$ reduction. 


\subsection{SuPPlementary CEMENTITIOUS MATERIAls (SCM)}

There are many different waste/by-product materials generated from different industries and in some cases these materials can be quite hazardous if not disposed correctly. However, the disposal of these materials is expensive and takes time, which leaves the waste in the environment for even longer. Therefore, many companies have started studying and implementing reuse of some of these products. There are a number of SCMs that are currently being investigated within the concrete production process such as Slag, Silica Fume and Fly-Ash (Aprianti, 2017). These recycled by-products have also shown possibilities of reducing the amounts of $\mathrm{CO}_{2}$ emitted into the atmosphere during cement production. However, there is discussion on which SCM is more effective for concrete construction.

\subsubsection{Slag}

Slag is a waste by-product that is generated during the smelting and/or purifying of ore. One of the biggest recycling options for slag is in cement production, as it provides environmental and economic advantages (Shi et al., 2008). The analysis of the life cycle of cement and concrete in construction compared to cement with slag showed a $22 \%$ $40 \%$ reduction in greenhouse gases released depending on the percentage of slag used (Crossin, 2015). Also, the price of slag compared to normal cement is seen to be the same according to studies conducted in both Australia and the US with the unit price per tonne increasing by US $\$ 20$ from 2005 to 2011 (van Oss, 2011). However, recently market data has shown regular cement pricing drop with slag staying the same (Crossin, 2015).

However, slag may have a negative impact on concrete properties. For instance, the permeability of the concrete has shown to decrease as the volume of the slag cement increases (Sharif and Alvi, 2016). In addition, the replacement of general portland cement with slag cement has resulted in a decrease in shrinkage in the short term (Yuan et al., 2015). The use of slag has also proven to cause time delays in projects as the setting time with slag is reported to be much longer than standard concrete prepared using OPC. When implemented in large construction projects, this can be a real issue as it can cause long unwanted delays to project schedule (Shi et al., 2008).

\subsubsection{Silica Fume}

Silica fume is generated through the smelting process of silicon metal and ferrosilicon alloys and is viewed as a valuable by-product that can be reused in other industries (Telford, 1988). Silica fume, like slag, is seen as an environmental hazard when disposed of and dumped in landfills. Silica fume in concrete has proven to provide efficient and effective strength and bonding properties for concrete while also being beneficial for shotcrete application (Siddique, 2011). However, the cost of implementing silica fume is more expensive than regular portland cement in concrete. Siddique (2011) explores the effect silica fume has on concrete properties and highlights how the silica fume enhanced the strength properties of high performance concrete structures. The advantages of using silica fume are increased toughness of the concrete, increase in concrete durability, much higher compressive strength and extremely high resistance to chemical attacks like acids.

\subsubsection{Fly-Ash}

Fly-ash is a waste product produced from coal-fired power stations that operate to produce energy (Brown et al., 2018). Fly-ash in the cement mixture has shown to be cost effective, energy conserving and environmentally sustainable (Mehta and Gjorv, 1982). 
Fly-ash accounts for approximately $75 \%$ of the total ash produced in the world and has been growing exponentially since the 1920 s when coal operated power plants were first introduced (Joshi and Lothia, 1997). About 500 million tonnes, which is about $16 \%$ of the produced fly-ash globally, is used for alternate purposes like concrete production and the rest is being dumped into landfills (Ahmaruzzaman, 2010).

Fly-ash alters the properties of the concrete mix, making it stronger when more fly-ash is introduced. Different percentages of fly-ash in concrete present differing properties for the mixture and hence multiple purposes, however, the maximum amount that can be used currently without having any structural issues is 35\% replacement (Jones et al., 2011). Islam and Islam (2013) found that the permeability and strength of the concrete increases with adding more fly-ash, but both will decrease once it goes beyond $30 \%$. Fly-ash will be the focus of this study due to its increasing usage and advantages highlighted previously.

\section{RESEARCH METHODOLOGY}

A case study approach was used for data collection purposes of this study. Two case studies of two contractor companies were selected. Within each case study, two separate project data sets with a total of 20 projects were studied. For comparison purpose, the first case study comprised of 10 projects used standard concrete using Ordinary Portland Cement (OPC), while the second case study consisted of other 10 projects with fly-ash introduced in the concrete. Further, the data collection process included detailed documentary review of bills of quantities of all the projects. The collected data was used to compare the carbon emissions between OPC used concrete and fly-ash used concrete to achieve the second objective of this study as shown in Figure 1.

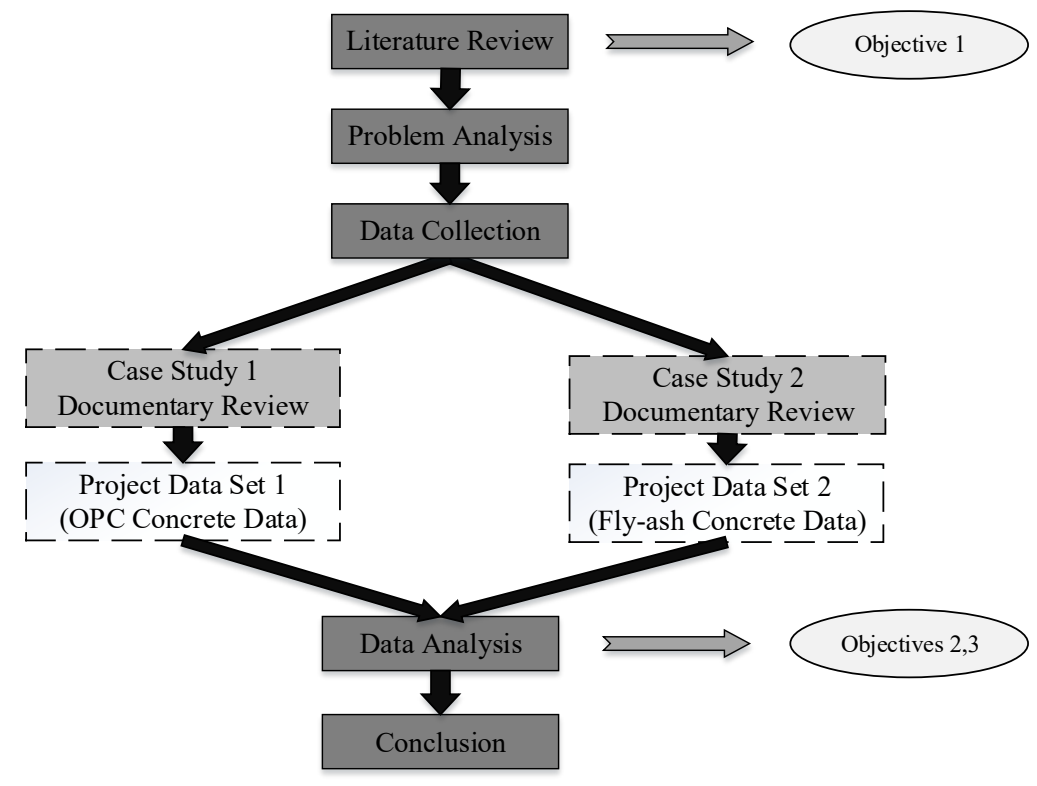

Figure 1: Research method framework of the study

To achieve the third objective, data was collected from concrete suppliers to carry out the financial analysis of fly-ash concrete and OPC concrete and investigate the cost effective type of concrete. The following section elaborately discusses the research findings of the study. 


\section{RESULTS AND DISCUSSION}

\subsection{ConCrete Usage in Different Projects Without Fly-ASH}

Figure 2 shows the data collected from 10 projects based in Sydney, which had used Portland cement (without fly-ash) in the concrete building elements. The figure shows the amounts of concrete used for each grade of concrete $(25 \mathrm{MPa}, 32 \mathrm{MPa}, 40 \mathrm{MPa}$ and $80 \mathrm{MPa}$ ) in each project (P1 to P10).

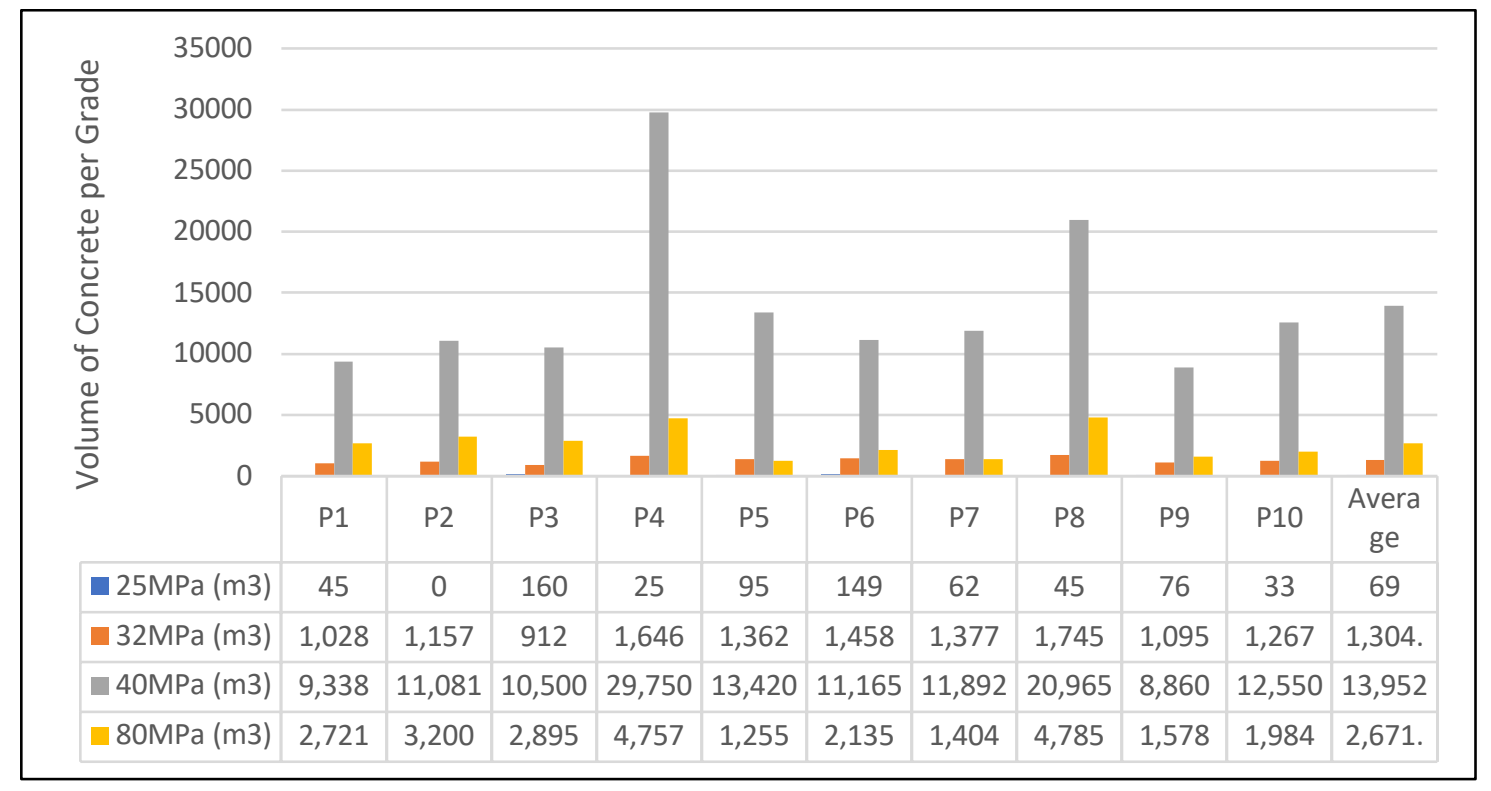

Figure 2: Concrete volume per grade of concrete with Ordinary Portland Cement

Considering the average volume of concrete usage in each grade of concrete, it is emphasised that the mostly used grade in concrete elements is $40 \mathrm{MPa}$ followed by $80 \mathrm{MPa}$. Besides when comparing the projects alone, this trend is noted except in the project $\mathrm{P} 5$, whereas $32 \mathrm{MPa}$ concrete has been used more than $80 \mathrm{MPa}$ concrete in P5.

\subsection{Carbon Emissions due to Usage of Portland Cement in CONCRETE}

Subsequent to the data collection carried out, it is required to estimate the $\mathrm{CO}_{2}$ emissions according to the concrete strength and how much difference there is if any at all. Therefore, as the initial step, the average volumes calculated for each grade of concrete across all the projects have to be converted to metric tonnes in order to calculate how much $\mathrm{CO}_{2}$ is emitted. It is calculated by multiplying the concrete volumes by 2.41 to convert cubic metres to tonne. On the other hand, the study carried out by National Ready Mixed Concrete Association (NRMCA) and Portland Cement Association (PCA) in the US stated that $\mathrm{CO}_{2}$ emissions account for between $5 \%$ and $13 \%$ of concrete produced, varying according to concrete grade as follows; $25 \mathrm{MPa}-5 \%$; $32 \mathrm{MPa}-6 \%$; $40 \mathrm{MPa}-7 \%$; and $80 \mathrm{MPa}-11 \%$ (NRMCA, 2008).

After incorporating the above factors, calculations were carried out to find out the $\mathrm{CO}_{2}$ emissions accounted by each concrete grade as demonstrated in Table 1. 
Table 1: Average $\mathrm{CO}_{2}$ emissions per grade of concrete

\begin{tabular}{lcccc}
\hline & \multicolumn{4}{c}{$\mathbf{C O}_{2}$ Emissions per Concrete Grade } \\
\cline { 2 - 5 } & $\mathbf{2 5 M P a}$ & $\mathbf{3 2 M P a}$ & $\mathbf{4 0 M P a}$ & $\mathbf{8 0 M P a}$ \\
\hline Volume $\left(\mathrm{m}^{3}\right)$ & 69 & $1,304.7$ & $13,952.1$ & $2,671.4$ \\
Weight $(\mathrm{t})$ & 166.29 & $3,144.33$ & $33,646.25$ & $6,438.07$ \\
Percentage & $5 \%$ & $6 \%$ & $7 \%$ & $11 \%$ \\
$\mathrm{CO}_{2}$ Emissions $(\mathrm{t})$ & 8.31 & 188.66 & $2,355.24$ & 708.19 \\
\hline
\end{tabular}

As identified in the literature review, the higher the grade of concrete, the more $\mathrm{CO}_{2}$ that is released. This is because there is more Portland cement introduced in the higher the concrete grade. The sum in tonnage for each grade of concrete will later be compared with fly-ash concrete carbon emissions. The $40 \mathrm{MPa}$ concrete is a highly used concrete grade as it is very strong and is able to form many shapes easily. However, as shown on the graph, it releases a lot of $\mathrm{CO}_{2}$ especially compared to the weaker concrete grades. $80 \mathrm{MPa}$ concrete is used predominantly for the high structural load bearing components of the buildings to ensure no failures occur. 25MPa and $32 \mathrm{MPa}$ are not as common as the stronger concrete grades for this type of construction, as they present no structural advantages, even though they present less environmental impact.

\subsection{Concrete Usage in Projects With Fly-Ash}

Figure 3 displays the concrete volumes for the projects that contained fly-ash added into the concrete mixes. The results gathered from these concrete data will be used to compare against what was found previously with the OPC concrete mix to determine if fly-ash is beneficial environmentally.

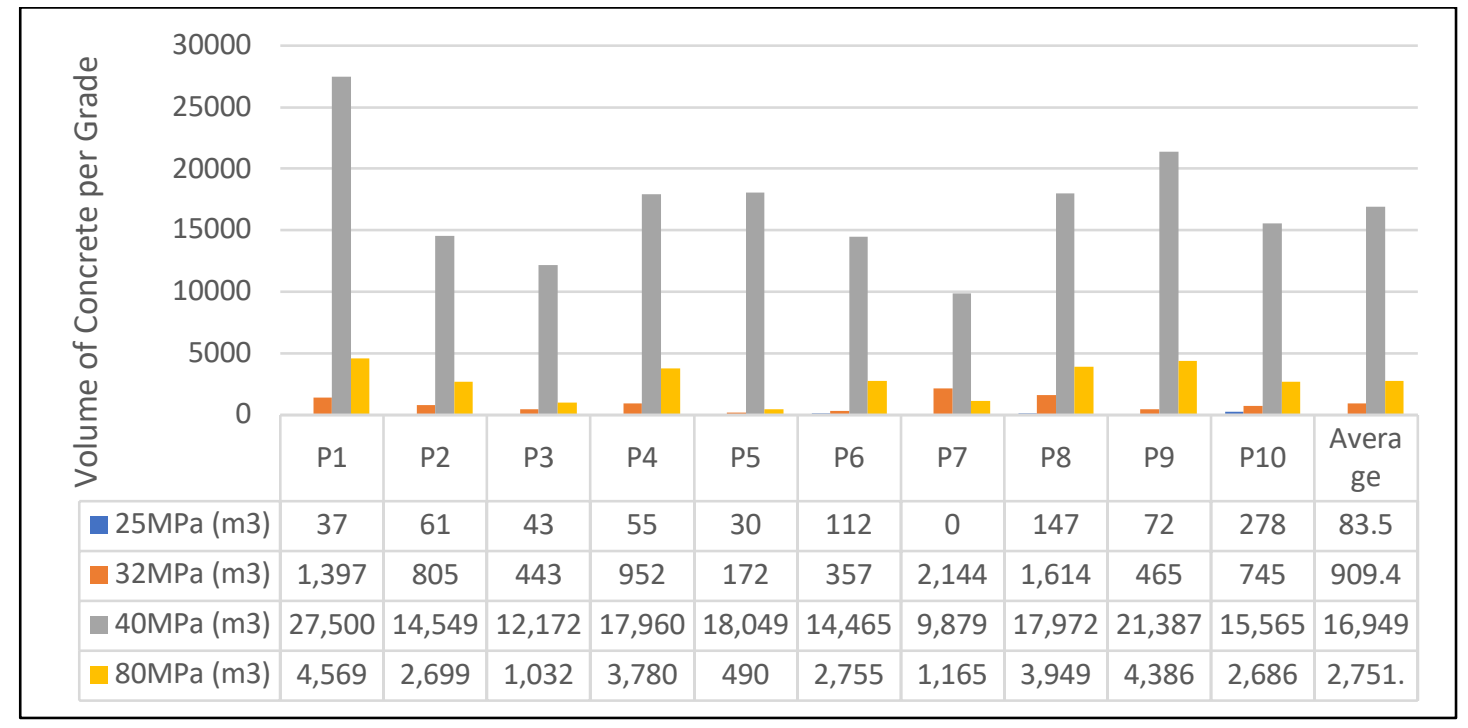

Figure 3: Concrete volume per grade of concrete with fly-ash

The total volumes of all the concrete grades for each project with fly-ash and the total average concrete is shown in Figure 3. These volumes are converted to tonnes so the $\mathrm{CO}_{2}$ content can be calculated to determine the overall embodied carbon of the concrete production process. It is evident that there are greater volumes of high grade concrete 
(40MPa and $80 \mathrm{MPa}$ ), due to the high concrete strength that is required for these specific projects.

\subsection{CARBON EMISSIONS REDUCTION DUE TO USAGE OF FLY-ASH IN CONCRETE}

The concrete data from the previous section had to be converted to tonnes due to the flyash content and cement content being measured in tonnes. The required fly-ash data were obtained from the Green Star reports where the fly-ash data is given in $\mathrm{kg}$ per cube of concrete. The cement to fly-ash ratios in concrete grades along with the project specific data were used to carry out several calculations to determine the cement reduction due to usage of fly-ash. A summary of the calculations carried out is demonstrated in Table 2.

Table 2: Average $\mathrm{CO}_{2}$ reductions per grade of concrete with fly-ash

\begin{tabular}{lcccc}
\hline & \multicolumn{4}{c}{ Carbon Reductions per Concrete Grade } \\
\cline { 2 - 5 } & $\mathbf{2 5 M P a}$ & $\mathbf{3 2 M P a}$ & $\mathbf{4 0 M P a}$ & $\mathbf{8 0 M P a}$ \\
\hline Average Concrete Volume $\left(\mathrm{m}^{3}\right)$ & 83.5 & 909.4 & $16,949.8$ & $2,751.1$ \\
Fly-Ash Content $(\mathrm{kg} / \mathrm{cube})$ & 80 & 90 & 90 & 140 \\
Fly-Ash Content $(\mathrm{t})$ & 6.68 & 81.846 & $1,525.48$ & 385.15 \\
Average Cement Content $(\mathrm{t})$ & 6 & 369 & 7,360 & 1,784 \\
Cement Reduction $(\mathrm{t})$ & 7.77 & 98.22 & $2,237.38$ & 530.97 \\
$\mathrm{CO}_{2}$ Reduction $(\mathrm{t})$ & 7.2 & 91.05 & $2,074.05$ & 492.21 \\
\hline
\end{tabular}

The results revealed that the fly-ash content increases in $\mathrm{kg}$ per cube, the higher the concrete grade, due to the need for the higher strength properties. This also then reduces the total amount of portland cement used in the process. Furthermore, the results demonstrate the total amounts of cement reduced on average for the studied projects, where 'for every $1000 \mathrm{~kg}$ of cement produced $927 \mathrm{~kg}$ of $\mathrm{CO}_{2}$ is released', the amount of $\mathrm{CO}_{2}$ that is reduced was calculated. From the table it is evident that the savings for the $40 \mathrm{MPa}$ concrete is substantial because of the amount of concrete used in this grade for these projects, where mostly it is used for elements in substructure and superstructure. In summary, the findings depict how much is being saved in carbon emissions with these large projects that have used fly-ash in concrete.

\subsection{Financial ANALYSIS OF FLY-ASH in CONCRETE}

Implementing new design techniques that may appear beneficial in one category, may affect another area of business negatively. Fly-ash in concrete is environmentally beneficial; however, it may present to be costly, which is not ideal for project managers and construction companies. Multiple rates per cube of concrete were obtained from multiple concrete suppliers and subsequently, an average rate (in Australian Dollar) was formed for fly-ash and OPC used concrete as illustrated in Table 3. Together with this, a comparison was carried out to determine whether fly-ash is financially beneficial as well as environmentally. The pricing is tabulated under each concrete grade as the fly ash and cement content vary according to the grade of concrete. 
Table 3: Rates per cube for different concrete grades

\begin{tabular}{lcccc}
\hline & \multicolumn{4}{c}{ Prices per Concrete Grade (\$/cube) } \\
\cline { 2 - 5 } & $\mathbf{2 5 M P a}$ & $\mathbf{3 2} \mathbf{M P a}$ & $\mathbf{4 0 M P a}$ & $\mathbf{8 0 M P a}$ \\
\hline OPC Concrete & 224 & 232 & 236 & 248 \\
Fly-Ash Concrete & 229 & 237 & 241 & 253 \\
\hline
\end{tabular}

The OPC concrete rates were provided by concrete suppliers and they are showing a gradual increase in price with the higher concrete grade. These rates were compared with multiple concrete suppliers and also construction estimating textbooks with current rates in Sydney. The concrete rates are subject to increase within the next 12 months, as they do every year, as indicated in the Consumer Price Index (CPI). The data collection process for the fly-ash rates were obtained from more specialist concrete suppliers as not all concrete suppliers have the option of providing fly-ash. Similar to the OPC used concrete mix, fly-ash concrete price increases as the concrete grade gets higher.

The concrete pricing for fly-ash concrete is about $2.1 \%$ more expensive than OPC concrete (refer to Table 3). This is due to the difficulty of obtaining fly-ash compared with Portland cement. Portland cement is readily available and stocked in many concrete plants, however, fly-ash is a special product that is generated at coal plants that need to be transported from specific locations. Therefore, although fly-ash is an environmentally friendly by-product for concrete production, it is not a cost effective option for Sydney based construction companies. Figure 4 shows the pricing comparison of the concrete rates in more detail.

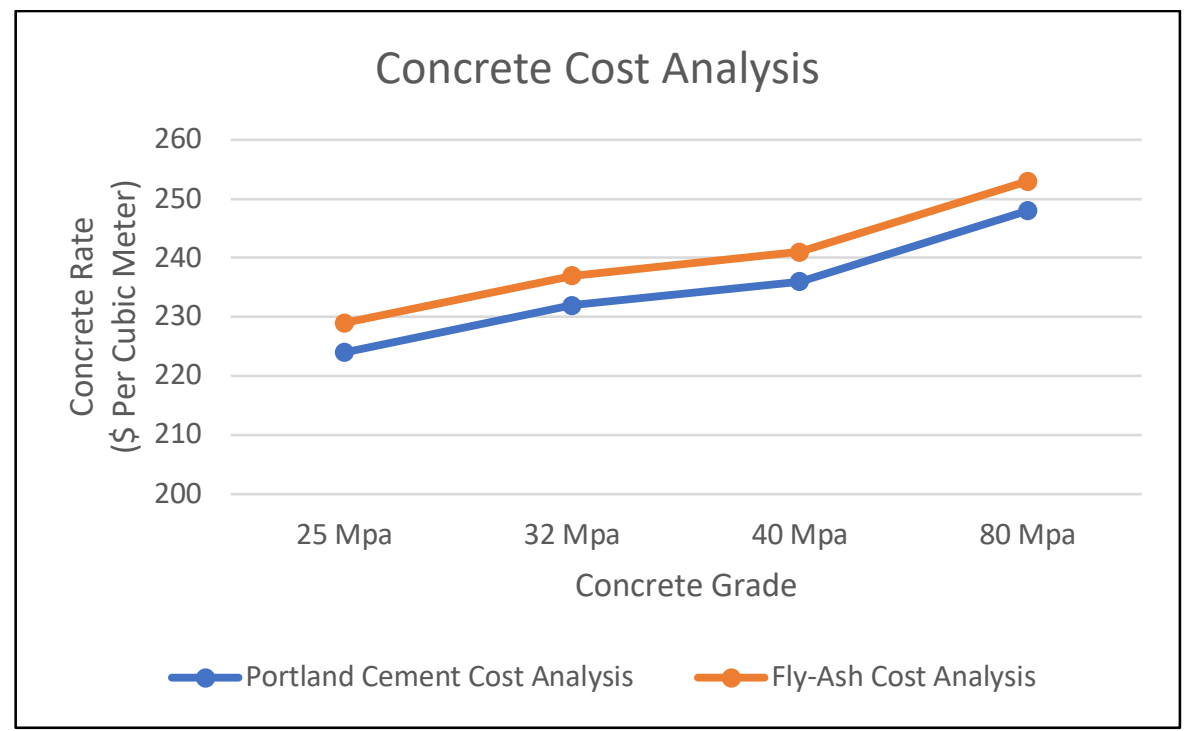

Figure 4: Sample graph of the costing analysis for fly-ash and Portland cement

According to Figure 4, the trend shows both lines increasing in price per grade of concrete at the exact same rate. In general, a standard percentage based on logistics and a margin is added to the OPC concrete rates when calculating the rate of fly-ash. In summary, though fly-ash concrete provided an environmentally friendly result by reducing the carbon emissions, it ultimately results in a higher cost compared to Portland cement concrete. 


\section{CONCLUSIONS}

The principal aim of this research study was to analyse the impacts of fly-ash in concrete on carbon emissions. Initially, a literature review was conducted to compare the different SCMs such as fly-ash, silica fume and slag, to determine the most appropriate SCM for this research. The findings revealed that environmentally, fly-ash would be more ideal for concrete construction. Also, in regard to the properties of the concrete finish, it would provide the same or more strength than Portland cement.

The results of the environmental analysis through the usage of fly-ash in concrete were subject to large amounts of data collected through bills of quantities of various projects completed in Sydney and Western Sydney. Subsequently, the carbon emissions between 10 projects using OPC concrete and 10 projects using fly-ash were compared and carbon reduction was calculated to identify where the most carbon savings occur. The calculations of the study revealed that fly-ash provides environmental benefits and it can be recommended for construction companies to use it. Furthermore, savings for the $40 \mathrm{MPa}$ concrete is substantial due to the usage of large amounts of concrete in this grade for substructure and superstructure elements in these projects. Subsequently, the financial analysis of OPC concrete and fly-ash used concrete was carried out and the result was not favourable as fly-ash was proven to be a less cost effective method than OPC concrete. Similarly, implementing of fly-ash into Envisia and Geopolymer concrete to investigate the effect of fly-ash in these types of concrete would be an interesting area to be researched on in the future.

\section{ACKNOWLEDGEMENT}

This paper presents the research findings of an undergraduate research study carried out at Western Sydney University.

\section{REFERENCES}

Ahmaruzzaman, M. 2010. A review on the utilization of fly ash. Progress in Energy and Combustion Science, 36(3), 327-363.

Aprianti, E., 2017. A huge number of artificial waste material can be supplementary cementitious material (SCM) for concrete production-a review part II. Journal of Cleaner Production, 142, pp.4178-4194.

Brown, L., Perera, S. and Rodrigo, M.N.N., 2018. Brownfield Redevelopment: A Dual Currency Analysis of Soil Stabilisation Methods. 7th World Construction Symposium 2018: Built Asset Sustainability: Rethinking Design, Construction and Operations, Colombo, Sri Lanka, 29 June-1 July 2018, pp.116125.

Crossin, E., 2015. The greenhouse gas implications of using ground granulated blast furnace slag as a cement substitute. Journal of Cleaner Production, 95, pp.101-108.

International Energy Agency. 2019. Cement Emissions, Cement Industry Federation. Available from: http://cement.org.au/SustainabilityNew/ClimateChange/CementEmissions.aspx [Accessed 8 October 2019]

Islam, M.M. and Islam, M.S., 2013. Strength and durability characteristics of concrete made with fly-ash blended cement. Australian Journal of Structural Engineering, 14(3), pp.303-319.

Jones, R., McCarthy, M. and Newlands, M. 2011. Fly ash route to low embodies $\mathrm{CO}_{2}$ and implications for concrete construction. In: Robl, T. and Adams, T. (Eds.) World of Coal Ash Conference, Denver, USA, 9-12 May 2011, pp.1-14.

Joseph, P. and Tretsiakova-McNally, S., 2010. Sustainable Non-Metallic Building Materials. Sustainability, 2(2), pp.400-427. 
Joshi, R.C. and Lothia, R.P., 1997. Fly ash in concrete: production, properties and uses. In: Advances in concrete technology, vol. 2. Canada: Gordon and Breach Science Publishers.

Juenger, M. and Siddique, R., 2015. Recent advances in understanding the role of supplementary cementitious materials in concrete. Cement and Concrete Research, 78, pp.71-80.

McLellan, B., Williams, R. and Lay, J., 2011. Costs and carbon emissions for geopolymer pastes in comparison to ordinary portland cement. Journal of Cleaner Production, 19(9), pp.1080-1090

Mehta, P. and Gjorv, O., 1982. Properties of Portland cement concrete containing fly ash and condensed silica-fume. Cement and Concrete Research, 12(5), pp.587-595.

Mehta, P.K., 2002. Greening of the concrete industry for sustainable development, Concrete International. Available from: http://maquinamole.net/EcoSmartconcrete.com/docs/trmehta02.pdf [Accessed 22 March 2018]

NRMCA, 2008. Concrete $\mathrm{CO}_{2}$ Fact Sheet. USA: NRMCA.

Rodrigo, M.N.N., Perera, S., Senaratne, S., and Jin, X., 2019. Embodied Carbon Mitigation Strategies in Construction Industry. CIB World Building Congress 2019. Hong Kong SAR, China. 17-21 June 2019, pp.1-10.

Sentowski, J.T., 2009. Concrete materials: properties, performance and applications. New York: Nova Science Publishers.

Sharif, M.B. and Alvi, M.H., 2016. Performance of locally available slag cement as supplementary cementitious material. NED University Journal of Research. 13(2), pp.23-30.

Shi, C., Meyer, C. and Behnood, A., 2008. Utilisation of copper slag in cement and concrete. Resources, Conservation and Recycling, 52(10), pp.1115-1120.

Siddique, R., 2011. Utilization of silica fume in concrete: Review of hardened properties. Resources, Conservation and Recycling, 55(11), pp.923-932.

Telford, T. 1988. Condensed silica fume in concrete. London: Thomas Telford Ltd.

Worrell, E., Price, L. and Martin, N., 2001. Energy efficiency and carbon dioxide emissions reduction opportunities in the US iron and steel sector, Energy, 26(5), pp.513-536.

Van Oss, H.G., 2011. USGS Minerals Information: Cement. Statistics Information. United States Geological Survey.

Yuan, J., Lindquist, W., Darwin, D., and Browning, J., 2015. Effect of slag cement on drying shrinkage of concrete. ACI Materials Journal, pp.267-276. 